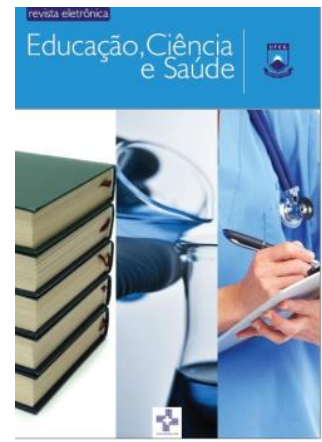

EDUCAÇÃO CIÊNCIA E SAÚDE

http://dx.doi.org/10.20438/ecs.v5i2.191

\title{
ASSISTÊNCIA HUMANIZADA E O ACOLHIMENTO DE PROFISSIONAIS DE ENFERMAGEM NA TERAPIA INTENSIVA: REVISÃO INTEGRATIVA
}

\author{
Lília Costa Nascimento ${ }^{1}$, Adriana Montenegro de Albuquerque ${ }^{2}$ \\ ${ }^{1}$ Curso de Bacharelado em Enfermagem, Unidade Acadêmica de Saúde, Universidade Federal \\ de Campina Grande, Cuité-PB, Brasil. \\ ${ }^{2}$ Prof ${ }^{a}$ Unidade Acadêmica de Enfermagem, Universidade Federal de Campina Grande, Cuité, \\ PB, Brasil. \\ Email para correspondência: liliac323@gmail.com
}

\begin{abstract}
Resumo
É importante abordar a necessidade da humanização e do acolhimento em terapia intensiva, pois estes cuidados não envolvem somente o cuidado ao paciente, e sim, estende-se que estão envolvidos no processo saúde-doença, a família, equipe multiprofissional e o ambiente. Objetivou-se analisar na produção científica artigos sobre o cuidado humanizado que é prestado ao paciente e família no ambiente de Terapia Intensiva e discutir como estas medidas de acolhimento são apresentáveis para a literatura cientifica. Trata-se de uma revisão integrativa, com busca nas bases de dados indexadoras: BVS, LILACS, BDENF e Medline, utilizando os descritores "Humanização da Assistência", "Unidades de Terapia Intensiva", "Cuidados de Enfermagem". Incluíram-se publicações entre 2010 a 2018, no idioma português, contabilizando uma amostra de 10 estudos. Destacam-se a importância e as dificuldades de se propagar um cuidado humanizado e acolhedor tanto para o paciente quanto para sua família, repassar as informações de maneira clara e estar disponível para escutar são medidas simples que podem acarretar uma grande diferença para quem esta sendo cuidado. O impacto desta revisão está em constatar e identificar intervenções efetivas para implementação da humanização nos cuidados a pacientes críticos e familiares mesmo com a criação de políticas e programas de humanização.
\end{abstract}

Palavras-chave: Humanização da Assistência, Unidades de Terapia Intensiva, Cuidados de Enfermagem.

\begin{abstract}
It is important to address the need for humanization and care in intensive care, since this care does not only involve patient care, but rather, it is understood that they are involved in the health-disease process, the family, the multiprofessional team and the environment. The objective was to analyze in the scientific production articles on the humanized care that is provided to the patient and family in the
\end{abstract}




\begin{abstract}
Intensive Care environment and to discuss how these reception measures are presentable for the scientific literature. It is an integrative review, with search in the index databases: VHL, LILACS, BDENF and Medline, using the descriptors "Humanization of Care", "Units of Intensive Care", "Nursing Care". Publications were included between 2010 and 2018 in the Portuguese language, accounting for a sample of 10 studies. The importance and difficulties of propagating a humane and welcoming care for both the patient and his family are emphasized, as well as to pass on the information in a clear way and to be available to listen are simple measures that can make a big difference for those who are being cared for. The impact of this review is to verify and identify effective interventions for the implementation of humanization in the care of critical and family patients, even with the creation of humanization policies and programs
\end{abstract}

Keywords: Humanization of Care, Intensive Care Units, Nursing Care.

\title{
1 Introdução
}

As Unidades de Terapia Intensiva (UTIs) foram criadas em virtude da alta complexidade do conhecimento biomédico, juntamente com os avanços tecnológicos proporcionando assim uma melhora na qualidade do cuidado, locais com as UTIs propiciam uma melhora na recuperação e sobrevivência de pacientes (COSTA, FIGUEIREDO, SCHAURICH, 2009).

É importante abordar a necessidade da humanização e do acolhimento em UTIs, pois estes cuidados não envolvem somente o cuidado ao paciente, e sim, estende-se a todos que estão envolvidos no processo saúde-doença, englobando assim a família, equipe e multiprofissional e o ambiente (SILVA et al., 2010).

A implantação da Politica Nacional de Humanização (PNH), pelo Ministério da Saúde visa fomentar trocas solidárias para uma melhor produção de saúde e a produção de sujeitos pautando-se em três princípios inseparabilidade entre atenção e a gestão, transversalidade e autonomia protagonista entre os sujeitos, frente a tudo isso que a PNH presa (BRASIL, 2003).

Já de acordo com o Programa Nacional de Humanização na Assistência Hospitalar (PNHAH) o mesmo tem como propósito um conjunto de ações interligadas que visa mudar imprescindivelmente o padrão de assistência ao usuário nos hospitais públicos do Brasil, contribuindo desta forma para uma melhora da qualidade e eficácia dos serviços hoje prestados. Procurando desta forma, propagar uma nova cultura de humanização nas redes de atenção hospitalar, tendo como principal objetivo capacitar os profissionais dos 
hospitais para um novo conceito de assistência à saúde que valorize a vida humana (BRASIL, 2001).

Já no que se refere ao acolhimento de qualidade este visa atender a todos que procuram os serviços de saúde, ouvindo assim seus pedidos e assumindo no serviço uma postura capaz de acolher, escutar e compactuar, dando respostas adequadas às necessidades dos usuários hospitalizados e a seus familiares (MARTINS et al., 2008 ).

Nos dias atuais, os cuidados prestados de forma humanizada tem se tornado cada vez mais urgente, como também desafiante, por isso vários estudos destacam a necessidade de recuperar a essência do cuidado humanizado, levando em consideração os aspectos biopsicossocioespiritual como também a individualidade de cada paciente. A UTI vem gradualmente obtendo mudanças, fazendo com que os profissionais que atuam nela possam estar mais conscientes de que a técnica isoladamente não e suficiente para recuperação dos pacientes em estado crítico (OLIVEIRA et al., 2013).

O estudo de Costa, Figueiredo e Schaurich (2009) revela fatores negativos para um bom acolhimento de forma humanizada como o tempo prolongado na UTI, no qual muito das vezes a técnica se sobressaia em relação aos aspectos de cuidado humanizado pelo fato de muitos profissionais da saúde estar envolvidos basicamente com equipamentos superdesenvolvidos esquecendo, assim, que por trás destes equipamentos encontra-se um ser humano, que de forma geral não se limita apenas ao biológico, e sim, há um indivíduo que deve ser visto e tratado holisticamente em todas as suas dimensões.

Diante deste contexto, esta revisão integrativa tem como objetivo analisar na produção científica artigos sobre o cuidado humanizado que é prestado ao paciente e família no ambiente de Terapia Intensiva e discutir como estas medidas de acolhimento são apresentáveis para a literatura cientifica.

\section{Métodos}

Revisão integrativa da literatura, construída a partir de fontes secundárias, no período de Outubro a Novembro de 2018. 
Para guiar a revisão integrativa formularam-se as seguintes questões norteadoras: Quais as fragilidades estão sendo apontadas para a falta de humanização é acolhimento por parte dos enfermeiros nos cuidados nas UTIs relacionadas aos estudos científicos?

Para seleção dos artigos foram utilizadas como bases de dados, a saber: Biblioteca virtual em Saúde (BVS), Literatura Latino Americana e do Caribe em Ciências da Saúde (LILACS), Bases de Dados de Enfermagem (BDENF), Medline. Buscou-se o levantamento de artigos completos utilizando os seguintes descritores (DeCS): "Humanização da Assistência", "Unidades de Terapia Intensiva", "Cuidados de Enfermagem", o operador booleano AND foi utilizado entre os três descritores para aumentar o escopo da revisão.

Os critérios de inclusão para a busca dos artigos foram: artigos publicados na íntegra, em língua vernácula, disponível on-line entre os anos de 2010 e 2018, que abordassem no título ou resumo a temática avaliada. E, foram excluídas da amostra, monografias, dissertações, teses, artigos em inglês e artigos com o ano de publicação anterior a 2010. Nesta ótica, a análise temática segue as seguintes etapas de organização: pré-análise, onde é realizada a organização e leitura flutuante do material, exploração do material, tratamento dos resultados, interpretação e categorização dos conteúdos.

Sendo encontrados, inicialmente, 173 artigos, dos quais foram filtrados por idioma português, texto na íntegra e ano de 2010 a 2018, destes foram excluídos 133, por não apresentar os critérios solicitados, restando 40 publicações, no qual destas só foram utilizadas 10 , sendo novamente excluídos os resumos, artigos em inglês, e outros que referiam à temática, porém em outro cenário hospitalar.

O instrumento de coleta de dados para a seleção da amostra e da análise dos estudos foi realizado por meio de critérios que especificava título, autor, ano de publicação, periódico, metodologia, objetivo geral e resultados.

A apresentação desta revisão e a discussão dos dados foram realizadas de forma de quadro e descritiva com intuito de permitir ao leitor a avaliação crítica dos resultados obtidos. 


\section{$3 \quad$ Resultados e Discussões}

O quadro 1 apresenta os artigos selecionados nesta revisão integrativa demonstrando uma visão geral da amostra.

Quadro 1: Distribuição dos artigos selecionados apresentando autor e ano, revista, método, título. Cuité, 2018.

\begin{tabular}{|c|c|c|c|c|}
\hline Nr. & Autor e Ano & Revista & Método & Título \\
\hline 1 & $\begin{array}{l}\text { Silva, Santos, } \\
2010\end{array}$ & $\begin{array}{l}\text { Esc } \\
\text { Anna } \\
\text { Nery }\end{array}$ & \begin{tabular}{|l|} 
Estudo \\
sociopoética
\end{tabular} & $\begin{array}{l}\text { Expectativas de familiares de } \\
\text { clientes em Unidade de } \\
\text { Terapia Intensiva sobre o } \\
\text { atendimento em saúde: } \\
\text { estudo sociopoético }\end{array}$ \\
\hline 2 & $\begin{array}{l}\text { Maestri et al., } \\
2012\end{array}$ & $\begin{array}{l}\text { Rev. } \\
\text { Enferm. } \\
\text { UERJ }\end{array}$ & Qualitativa & $\begin{array}{l}\text { Estratégias para o } \\
\text { acolhimento dos familiares } \\
\text { dos pacientes na unidade de } \\
\text { terapia intensiva }\end{array}$ \\
\hline 3 & $\begin{array}{l}\text { Backes et al., } \\
2012\end{array}$ & $\begin{array}{l}\text { Esc } \\
\text { Anna } \\
\text { Nery }\end{array}$ & \begin{tabular}{l|} 
Estudo \\
qualitativo \\
Utilizou a \\
Grounded \\
Theory
\end{tabular} & $\begin{array}{l}\text { O cuidado intensivo } \\
\text { oferecido ao paciente no } \\
\text { ambiente de unidade de } \\
\text { terapia intensiva. }\end{array}$ \\
\hline 4 & $\begin{array}{l}\text { Silva et al., } \\
2012\end{array}$ & $\begin{array}{l}\text { Esc } \\
\text { Anna } \\
\text { Nery }\end{array}$ & $\begin{array}{l}\text { Pesquisa } \\
\text { qualitativa } \\
\text { com } \\
\text { entrevista } \\
\text { semi- } \\
\text { estruturada }\end{array}$ & $\begin{array}{l}\text { Discursos de enfermeiros } \\
\text { sobre humanização na } \\
\text { unidade de terapia intensiva }\end{array}$ \\
\hline 5 & $\begin{array}{l}\text { Camponogara } \\
\text { et al., } 2013\end{array}$ & $\begin{array}{l}\text { J. Res: } \\
\text { fundam. } \\
\text { Care. } \\
\text { Online }\end{array}$ & $\begin{array}{l}\text { Estudo } \\
\text { descritivo } \\
\text { com } \\
\text { abordagem } \\
\text { qualitativa }\end{array}$ & $\begin{array}{l}\text { Percepções e necessidades } \\
\text { de familiares de pacientes } \\
\text { internados em unidade de } \\
\text { terapia intensiva }\end{array}$ \\
\hline 6 & $\begin{array}{l}\text { Passos et al., } \\
2015\end{array}$ & $\begin{array}{l}\text { Rev } \\
\text { enferm }\end{array}$ & $\begin{array}{l}\text { Estudo } \\
\text { qualitativo e }\end{array}$ & $\begin{array}{l}\text { O acolhimento no cuidado à } \\
\text { família numa unidade de }\end{array}$ \\
\hline
\end{tabular}




\begin{tabular}{|c|c|c|c|c|}
\hline & & UERJ & descritivo & terapia intensiva \\
\hline 7 & $\begin{array}{l}\text { Silveira, } \\
\text { Contim, } 2015\end{array}$ & $\begin{array}{l}\text { J. Res: } \\
\text { fundam. } \\
\text { Care. } \\
\text { Online }\end{array}$ & $\begin{array}{l}\text { Estudo } \\
\text { bibiométrico } \\
\text { descritivo } \\
\text { de recorte } \\
\text { transversal }\end{array}$ & $\begin{array}{l}\text { Educação em saúde e } \\
\text { prática humanizada da } \\
\text { enfermagem em unidades de } \\
\text { terapia intensiva: estudo } \\
\text { bibliométrico }\end{array}$ \\
\hline 8 & $\begin{array}{l}\text { Reis, Sena, } \\
\text { Fernandes, } \\
2016\end{array}$ & $\begin{array}{l}\text { J. Res: } \\
\text { fundam. } \\
\text { Care. } \\
\text { Online }\end{array}$ & $\begin{array}{l}\text { Revisão } \\
\text { Integrativa }\end{array}$ & $\begin{array}{l}\text { Humanização do cuidado } \\
\text { nas unidades de terapia } \\
\text { intensiva: revisão integrativa }\end{array}$ \\
\hline 9 & $\begin{array}{l}\text { Carli et al., } \\
2018\end{array}$ & $\begin{array}{l}\text { J. Res: } \\
\text { fundam. } \\
\text { Care. } \\
\text { Online }\end{array}$ & $\begin{array}{l}\text { Qualitativo } \\
\text { de revisão } \\
\text { bibliográfica } \\
\text { sistemática }\end{array}$ & $\begin{array}{l}\text { O tema da humanização na } \\
\text { terapia intensiva em } \\
\text { pesquisas na saúde }\end{array}$ \\
\hline 10 & $\begin{array}{l}\text { Figueiredo et } \\
\text { al., } 2018\end{array}$ & $\begin{array}{l}\text { Revista } \\
\text { Saúde } \\
\& \\
\text { Ciência } \\
\text { online }\end{array}$ & $\begin{array}{l}\text { Revisão } \\
\text { Integrativa }\end{array}$ & $\begin{array}{l}\text { Cuidado humanizado ao } \\
\text { paciente crítico: uma revisão } \\
\text { integrativa }\end{array}$ \\
\hline
\end{tabular}

Fonte: Elaboração Própria, 2018.

Foram analisados 10 artigos que atenderam aos critérios de inclusão previamente estabelecidos, entre 2010 a 2018, no qual todas as publicações são brasileiras e não houve duplicidade de autores.

Nos anos de 2010, 2013 e 2016 obteve-se apenas um artigo em cada, dois artigos em 2015 e 2018, respectivamente, e destacam-se três artigos em 2012, não se observa nenhuma publicação em 2014.

Salienta-se 4 artigos publicados no periódico J. Res: fundam. Care. Online, 3 na Esc Anna Nery Rev Enferm, 2 na Rev enferm UERJ e 1 na Revista Saúde \& Ciência online.

Evidencia-se a metodologia diferenciada para os artigos selecionados, dentre esses 1 pesquisa sócio-poética, 2 revisões integrativas, 1 de revisão sistemática, 5 pesquisas qualitativas, 1 estudo bibliométrico, descritivo de 
recorte transversal, do total da amostra apenas um utilizou a Grounded Theory, abordando a enfermagem e pacientes em UTIs.

Quanto aos títulos das publicações destaca-se que 5 apresenta a palavra humanizado ou humanização. Observa-se 9 com unidade de terapia intensiva ou só terapia intensiva, 2 refere-se a acolhimento, 4 familiares ou família, 4 com a palavra cuidado, 1 Enfermagem e 1 enfermeiros. Ressalta-se que essas palavras foram de encontro com os descritores selecionados nessa pesquisa.

Diante disso, Passos et al (2015) indaga que é relevante saber que a UTI é um local que se propõe a prestar atendimento aos pacientes mais graves e críticos, se diferindo de outras unidades, tal ambiente é também considerado um local da rede hospitalar com aspecto triste, ao qual não afeta somente 0 paciente mais a família e profissionais de saúde presentes neste espaço.

Ratifica-se com o mesmo entendimento um estudo atual, no qual destaca que o estresse, o medo, a tristeza e a dor são características dadas a este local. Implica-se dizer que se os profissionais de saúde não transformarem o local em um ambiente mais humanizado, devido não perceber o ser humano como um indivíduo único, com necessidades específicas, isso pode transformar a assistência apenas tecnicista e não humanizada, o que interfere ainda mais no cuidado ao paciente, cabendo à equipe de profissionais discutirem esses aspectos, para que com isso o sofrimento, e o medo não se tornem algo incapacitante (CARLI, et al., 2018).

O quadro 2 descreve os objetivos e os principais resultados das publicações selecionadas.

Quadro 2: Distribuição dos artigos selecionados apresentando objetivos e resultados. Cuité, 2018.

\begin{tabular}{|c|lc|llll|}
\hline $\mathbf{N r}$ & \multicolumn{2}{|c|}{ Objetivo } & \multicolumn{4}{|c|}{ Resultados } \\
\hline 1 & Analisar a dimensão & Concluiu-se & que os & familiares \\
& imaginativa dos familiares de & expressaram & expectativas & positivas \\
& clientes hospitalizados em UTI, & em relação à internação do cliente, por \\
& identificando suas expectativas & meio do & acolhimento e e das \\
& sobre o atendimento de suas & informações recebidas. & & \\
& necessidades humanas pela & & & & \\
\end{tabular}




\begin{tabular}{|c|c|c|}
\hline & equipe de enfermagem. & \\
\hline 2 & $\begin{array}{lr}\text { Identificar quais são as } \\
\text { estratégias de acolhimento } \\
\text { implementadas } r \text { pelos } \\
\text { enfermeiros, aos familiares } \\
\text { dos pacientes na Unidade de } \\
\text { Terapia Intensiva. }\end{array}$ & $\begin{array}{l}\text { Os resultados deram origem a três } \\
\text { discursos: recepcionar os familiares na } \\
\text { admissão; o contato telefônico com os } \\
\text { familiares; e a relação dialógica no } \\
\text { horário de visitas. Entre as estratégias } \\
\text { adotadas encontram-se: preparar o } \\
\text { familiar para entrar na unidade; } \\
\text { informar por telefone quando ocorre } \\
\text { piora do quadro clínico e na alta; estar } \\
\text { presente a beira do leito durante a } \\
\text { visita para esclarecimento de dúvidas. }\end{array}$ \\
\hline 3 & $\begin{array}{l}\text { Compreender o cuidado } \\
\text { intensivo oferecido ao paciente } \\
\text { no ambiente de Unidade de } \\
\text { Terapia Intensiva Adulto. }\end{array}$ & $\begin{array}{l}\text { A teoria "Sustentando a vida no } \\
\text { ambiente complexo de cuidados em } \\
\text { UTI", foi delimitada por oito categorias, } \\
\text { das quais foi focalizada neste artigo a } \\
\text { categoria "Cuidando e monitorando o } \\
\text { paciente continuamente". Conclui-se } \\
\text { que o cuidado intensivo requer um } \\
\text { cuidado integral com os pacientes, que } \\
\text { vai além do cuidado técnico e inclui as } \\
\text { dimensões física, emocional, espiritual } \\
\text { e social do ser humano. }\end{array}$ \\
\hline 4 & $\begin{array}{l}\text { Identificar elementos da } \\
\text { prática dos enfermeiros de } \\
\text { terapia intensiva que dificultam } \\
\text { a implementação da } \\
\text { humanização da assistência, } \\
\text { analisando-os à luz da Política } \\
\text { Nacional de Humanização. }\end{array}$ & $\begin{array}{l}\text { Há dificuldades que indicam } \\
\text { necessidade de investimentos na } \\
\text { formação e na gestão institucional e do } \\
\text { cuidado, de modo que a política de } \\
\text { humanização seja efetivamente } \\
\text { implantada na UTI. }\end{array}$ \\
\hline 5 & $\begin{array}{l}\text { Conhecer as percepções e } \\
\text { necessidades dos familiares } \\
\text { de pacientes internados em }\end{array}$ & $\begin{array}{l}\text { Os dados evidenciam que os } \\
\text { familiares vivenciam sentimentos } \\
\text { contraditórios em relação à UTI. }\end{array}$ \\
\hline
\end{tabular}




\begin{tabular}{|c|c|c|}
\hline & unidade de terapia intensiva & $\begin{array}{l}\text { Embora os familiares a percebam } \\
\text { como um setor onde prevalece o medo } \\
\text { da morte, eles também a vem como o } \\
\text { setor onde se encontra a melhor } \\
\text { qualidade de cuidados. Os familiares } \\
\text { demonstram, principalmente, uma } \\
\text { necessidade de interação com a } \\
\text { equipe multiprofissional, por meio de } \\
\text { uma comunicação efetiva com os } \\
\text { profissionais. } \\
\text { necessidades dos familiares foram } \\
\text { conhecer fatos concretos sobre o } \\
\text { progresso do familiar, ter a certeza de } \\
\text { que o familiar está recebendo o melhor } \\
\text { tratamento, toalete próximo à sala de } \\
\text { espera e dia e horário de visitas } \\
\text { flexíveis. Houve implementação de } \\
\text { salas de acolhimento familiar, com } \\
\text { auxílio de grupos de apoio aos } \\
\text { familiares e de humanização, além da } \\
\text { implementação de informativos } \\
\text { visuais. }\end{array}$ \\
\hline 6 & $\begin{array}{l}\text { Descrever como a enfermeira } \\
\text { se apropria do acolhimento no } \\
\text { cuidado à família na unidade } \\
\text { de tratamento intensivo }\end{array}$ & $\begin{array}{l}\text { Destaca-se que a enfermeira } \\
\text { compreende a família como unidade } \\
\text { do cuidado, mas por não sentir-se } \\
\text { preparada, o acolhimento se restringe } \\
\text { a aplicar o histórico e anamnese na } \\
\text { admissão e atualizar informações } \\
\text { sobre o estado clínico dos pacientes } \\
\text { durante as visitas. }\end{array}$ \\
\hline 7 & $\begin{array}{l}\text { Abordar a participação do } \\
\text { Enfermeiro enquanto principal } \\
\text { cuidador e educador em saúde }\end{array}$ & $\begin{array}{l}\text { A humanização na UTI é uma tarefa } \\
\text { complexa por vários motivos, como o } \\
\text { elevado número de atividades que o }\end{array}$ \\
\hline
\end{tabular}




\begin{tabular}{|c|c|c|}
\hline & $\begin{array}{l}\text { inserido na Unidade de } \\
\text { Terapia Intensiva. }\end{array}$ & $\begin{array}{l}\text { enfermeiro executa na UTI, reduzindo } \\
\text { seu tempo de convívio com pacientes } \\
\text { e familiares, bem como para um } \\
\text { treinamento adequado de sua equipe. }\end{array}$ \\
\hline 8 & $\begin{array}{l}\text { Identificar o que a literatura } \\
\text { científica nacional tem } \\
\text { abordado acerca da } \\
\text { humanização do cuidado nas } \\
\text { Unidades de Terapia Intensiva } \\
\text { em bases de dados online, no } \\
\text { período de } 2009 \text { a } 2013 \text {. }\end{array}$ & $\begin{array}{l}\text { Infere-se que seis estudos foram } \\
\text { selecionados, nos quais os resultados } \\
\text { evidenciaram que a humanização no } \\
\text { cuidado contribui de maneira } \\
\text { significativa na recuperação do } \\
\text { paciente em UTI. Entretanto, há } \\
\text { dificuldades de efetivação a serem } \\
\text { superadas, sobretudo, relacionadas a } \\
\text { questões do paciente e seus } \\
\text { familiares, da equipe de enfermagem e } \\
\text { das instituições de saúde. Há } \\
\text { necessidade de capacitação e } \\
\text { sensibilização dos profissionais, } \\
\text { incremento de investimentos na } \\
\text { formação, gestão institucional e do } \\
\text { cuidado para melhorias na assistência } \\
\text { ao paciente crítico. }\end{array}$ \\
\hline 9 & $\begin{array}{l}\text { Sistematizar estudos } \\
\text { indexados no Scielo e Medline, } \\
\text { sobre humanização em } \\
\text { Unidade de Terapia Intensiva. }\end{array}$ & $\begin{array}{l}\text { A humanização em UTI ainda é um } \\
\text { desafio, a Enfermagem é uma das } \\
\text { áreas que se ocupa com esta prática, } \\
\text { o entendimento de que a humanização } \\
\text { envolve assistência, os processos e } \\
\text { condições de trabalho, vários são os } \\
\text { atores producentes e que há } \\
\text { interferentes na sua produção. }\end{array}$ \\
\hline 10 & $\begin{array}{l}\text { Caracterizar a produção } \\
\text { científica publicadas em } \\
\text { periódicos online, sobre o } \\
\text { processo de humanização e os }\end{array}$ & $\begin{array}{l}\text { No estudo, foi identificado que alguns } \\
\text { profissionais de enfermagem } \\
\text { desconhecem a Política Nacional de } \\
\text { Humanização. Observou-se que os }\end{array}$ \\
\hline
\end{tabular}




\begin{tabular}{|l|l|l|l|}
\hline $\begin{array}{l}\text { cuidados prestados ao } \\
\text { paciente que se encontra em } \\
\text { situações críticas de saúde. }\end{array}$ & $\begin{array}{l}\text { profissionais que demonstram algum } \\
\text { grau de conhecimento apresentam } \\
\text { dificuldades para implementação } \\
\text { desta, contudo acreditam que o } \\
\text { cuidado humanizado contribui de } \\
\text { maneira significativa na recuperação } \\
\text { do paciente. }\end{array}$ \\
\hline
\end{tabular}

Da amostra estudada o verbo que mais se destacou nos objetivos com 3 publicações foi "identificar" e os outros sem duplicidade, apresentando-se: analisar, compreender, conhecer, descrever, abordar, sistematizar e caracterizar. Salienta-se que esses verbos são os mais evidentes em publicações nacionais. Enquanto que os resultados variavam de acordo com os objetivos em pesquisa que apresentaram categorias e outras com o sumário dos pontos relevantes.

Pesquisa de revisão integrativa realça que as dificuldades para a implementação da humanização e acolhimento holístico em locais com as UTIs, estão relacionado ao fato do desrespeito e individualidade dos profissionais, outros fatores seria também, o não uso da identidade do paciente/não chamar pelo nome; conversar coisas desnecessárias no ambiente hospitalar ou muitas vezes indevidas; pelo fato da ambiência hospitalar não ofertar privacidade fazendo que haja a exposição do corpo do paciente. Tais fatores tornam-se contraditórios ao que diz à Política Nacional de Humanização $(\mathrm{PNH})$, quando indica que um ambiente acolhedor, resolutivo e humano na terapia intensiva é de extrema importância para a garantia da privacidade e conforto tanto dos pacientes como dos profissionais (REIS, SENA, FERNANDES, 2016).

Diante do dito, o objeto de estudo da PNH que é a evolução do homem em aperfeiçoar suas aptidões mostra-se pouco abordada nas instituições de ensino superior por motivos falhos, o que contribui para que estudantes saiam de sua graduação sem ter o conhecimento de como realizar um acolhimento humanizado, o que implica que esta temática seja incluída, ou melhor, 
trabalhada pelas instituições e assim seja voltada a formação crítico-reflexiva de profissionais da saúde (SILVA; SANTOS, 2010).

Assim, a humanização nos cuidados hospitalares vem trazer diversas metas, como a dignidade humana, o respeito, e a valorização da vida, pressupondo a transformação de uma maneira diferenciada de tratar 0 paciente. Contudo a Humanização só pode ser construída de modo que venha atender as singularidades e especificidades de cada ser, sendo um processo inerente à prática profissional com objetivo de oferecer o melhor tratamento possível (SILVEIRA; CONTIM, 2015).

Primeiramente, vale ressaltar que é de suma importância ter conhecimento que a UTI distingue-se de outros locais por ser um ambiente que exige de cada atuante um alto controle emocional, já que a vida e a morte a todo o momento são confrontadas, tal fato pode causar um desgaste emocional dos profissionais o que poderia influenciar no seu modo de cuidado, assim estes profissionais sentem a necessidade de serem mais fortes, o que pode estar relacionado com o fato de alguns profissionais serem ou se tornarem frios e com sentimento pouco humanizado (MAESTRI et al., 2012).

Corroborando com esse estudo, Rodrigues et al (2013) descreve que existe uma correlação com a falta de uma assistência humanizada prestada por profissionais da saúde com a insatisfação do enfermeiro inserido nas UTIs dos hospitais, pelo fato de estes profissionais serem muitas vezes multifacetados, submetidos a uma diversidade de atribuições e desconhecimento do que seja tratar humanamente, assim todos estes fatores eleva os níveis de estresse pessoais comprometendo, assim, o cuidado humanizado e o acolhimento prestado.

Neste ínterim o estudo bibliométrico realizado por Silveira e Contim (2015) refere que a sobrecarga na jornada de trabalho, juntamente com as formas de organização de alguns hospitais e as atribuições técnicas das atividades de enfermagem, levam estes profissionais a tornarem-se mais vulnerável e cada vez mais distante do que realmente importa, sendo que o desgaste de muitos profissionais da saúde torna-se evidente e interferem na forma de cuidar do paciente, tornando o cuidado negativo e imprudente. 
Outro estudo aviva que as limitações dos profissionais estão relacionadas á sua insatisfação com o emprego, ao qual contribui para uma ausência de motivação e a indiferença nos setores trabalhados, tais fatores elevam o nível de estresse dos profissionais levando assim ao descontentamento pela profissão, como também ao desconhecimento, causando uma reconfiguração da relação paciente e profissional (SILVA et al., 2012).

Ratificando com este estudo, Backes et al (2012) afirma que os profissionais, atuantes na UTI demostram criar um mecanismo de adaptação para seu trabalho, principalmente contra o sofrimento, passando a ser entendido como uma forma de insensibilidade, porém podendo interferir na forma do tratamento para com o paciente. Dessa forma, passando o paciente na UTI na maioria das vezes a ser tratado como um objeto de trabalho por profissionais, insensíveis, devido ao fato de se preocuparem mais com o fazer técnico do que com o próprio ser humano. Porém, outros fatores que interligados ao mau tratamento ao cuidado prestado poderia estar sendo justificado pelo acúmulo de serviço ou pela falta de organização das instituições.

Quanto ao quesito acolhimento aos familiares por profissionais atuantes na UTI, mostra-se em pesquisa que a prioridade atribuída ao acolhimento humanizado a paciente na visão de algumas enfermeiras entrevistadas no seu estudo estão apenas voltada aos equipamentos utilizados para o atendimento imediato e monitorização dos pacientes críticos (PASSOS et al., 2015).

Em estudo realizado por Maestri et al (2012) em hospitais, mostra que raros são os profissionais da saúde que dão valor à família e as enxergam como parte peculiar do cuidado. Esses aspectos vêm reforçar a necessidade de refletirmos sobre a procura de aprimoramento dos profissionais no modo de cuidar.

De tal forma, pode-se observar que a percepção dos enfermeiros quanto ao acolhimento aos familiares de seus pacientes ainda se dá de forma negativa, a família também necessita de um melhor acolhimento, necessitam de profissionais solidários, que tenham paciência e que se comuniquem lhes informando sobre seus pacientes, visto que a UTI transmite medo e apreensão para os familiares (FIGUEIREDO et al., 2018). 
Nesta perspectiva, familiares quando não são efetivamente informados, ou melhor, recepcionado por profissionais de saúde e em foco o enfermeiro que esta constantemente em contato com paciente/familiar estas podem também há vim a desenvolver problemas de saúde como: depressão; ansiedade; sentimento de culpa e sensação de impotência. Visto que informações repassadas pela equipe de profissionais, e a oportunidade de expressar seus sentimentos favorece o conforto e contentamento familiar. Posto isto, um acolhimento humanizado realizado por bons profissionais vai originar um vínculo mais estreito entre aquele que vai cuidar com aquele que precisa de cuidado, levando em consideração que esta prática deveria ser constante (PASSOS et al., 2015).

Portanto, a enfermagem enquanto profissão comprometida com processos e políticas de humanização do cuidado, precisa buscar uma prática que favoreça a participação e os cuidados qualificados ao paciente e sua família colaborando nas decisões e na assistência, promovendo, assim, a autonomia dos sujeitos (CAMPONOGARA et al ., 2013).

\section{Conclusão}

O estudo permitiu constatar que as medidas de humanização e acolhimento nas UTIs é de extrema importância tanto para os pacientes que ali estão quanto para seus familiares, que se angustiam com o adoecimento de seus parentes, quanto para a melhoria da assistência prestada pelos profissionais que estão em contato diariamente com os pacientes. Porém, notou-se que, mesmo com a criação da política e do programa de humanização há muitas dificuldades para implementação da assistência humanizada em ambiente hospitalar.

Contudo, cabe ao enfermeiro intensivista assumir-se um papel de orientador central, disseminando informações e cuidados de qualidade para família, pacientes e equipe, dando-Ihes assim orientações claras, precisas e estabelecendo uma efetiva relação de ajuda em reconhecer a subjetividade e a importância daqueles no acompanhamento do paciente crítico.

A assistência de enfermagem deverá reconhecer e cuidar do paciente e família em seu modo holístico com uma assistência integrada e humanizada 
em todos os sentidos. Assim, os enfermeiros que trabalham nas UTIs, podem e devem se voltar para o cuidado humanizado, visando atingir a integralidade, estando em suas mãos à prática de educação e saúde, e sendo os disseminadores de conhecimento e experiências.

\section{Referências}

BACKES, Marli Terezinha Stein et al. O cuidado intensivo oferecido ao paciente no ambiente de unidade de terapia intensiva. Esc Anna Nery, v. 16, n.4, p. 689 - 696, out-dez., 2012. Disponível em: < http://www.scielo.br/pdf/ean/v16n4/07.pdf > Acesso em: 14. Out. 2018.

BRASIL. Ministério da Saúde. Secretaria de Assistência à Saúde. Programa Nacional de Humanização da Assistência Hospitalar. Brasília: Ministério da Saúde, 2001.

BRASIL. Ministério da Saúde. Secretaria de Atenção à Saúde. Política Nacional de Humanização. Formação e intervenção - Brasília (DF): Ministério da Saúde, 2003.

CAMPONOGARA, Silviamar et al. Percepções e necessidades de familiares de pacientes internados em unidade de terapia intensiva. J. Res: fundam. Care. Online, v. 5 , n. 4, p.622-34, jul/set., 2013. Disponível em: < http://www.seer.unirio.br/index.php/cuidadofundamental/article/view/2309/pdf 971> Acesso em: 14. Out.2018.

CARLI, Bianca Silveira de et al. O tema da humanização na terapia intensiva em pesquisas na saúde. J. Res: fundam. Care. Online, v. 10, n. 2, p. 326-333. abr/jun., 2018. Disponível em: <http://www.seer.unirio.br/index.php/cuidadofundamental/article/view/6018/pdf_1> Acesso em: 15. Nov. 2018.

COSTA, Silvio Cruz.; FIGUEIREDO, Maria Renita Burg.; SCHAURICH, Diego. Humanização em unidade de terapia intensiva adulto (UTI): compreensões da equipe de enfermagem. Interface- Comunic., Saúde, Educ., v. 13, supl. 1, p.571-80, 2009. Disponível em: < http://www.scielo.br/pdf/icse/v13s1/a09v13s1.pdf > Acesso em: 14. Out. 2018. 
FIGUEIREDO, Maria do Carmo Clemente et al. Cuidado humanizado ao paciente crítico:uma revisão integrativa. Revista Saúde \& Ciência online, v. 7, n.1, p. 94-101., 2018. Disponível em: <http://150.165.111.246/revistasaudeeciencia/index.php/RSCUFCG/article/view/513/331> Acesso em: 15. Nov. 2018.

MAESTRI, Eleine et al. Estratégias para o acolhimento dos familiares dos pacientes na unidade de terapia intensiva. Rev. enferm. UERJ, Rio de Janeiro, v. 20, n. 1, p. 73-8, jan/mar., 2012. Disponível em: <http://www.facenf.uerj.br/v20n1/v20n1a13.pdf> Acesso em: 14. Out. 2018.

MARTINS, Josiane Jesus et. al. O acolhimento à família na Unidade de Terapia Intensiva: conhecimento de uma equipe multiprofissional. Rev. Eletr. Enf, v. 10, n. 4, p.1091-101, 2008.

Disponível em: $<$ http://www.fen.ufg.br/revista/v10/n4/v10n4a22.htm> Acesso em: 15. Nov.2018.

OLIVEIRA, Nara Elisa Souza et al. Humanização na teoria e na prática: a construção do agir de uma equipe de enfermeiros. Rev. Eletr. Enf, v. 15, n. 2, p. 334-43, abr/jun., 2013. Disponível em: < http://www.revenf.bvs.br/pdf/ree/v15n2/04.pdf > Acesso em: 14. Out. 2018.

PASSOS, Silvia Silva Santos et al. O acolhimento no cuidado a família numa unidade de terapia intensiva. Rev enferm UERJ, Rio de Janeiro, v. 23, n. 3, p. 368-74, mai/jun., 2015. Disponível em: < http://www.facenf.ueri.br/v23n3/v23n3a13.pdf> Acesso em: 14. Out. 2018.

REIS, Camila Calhau Andrade; SENA, Edite Lago Silva; FERNANDES, Marcos Henrique. Humanização do cuidado nas unidades de terapia intensiva: revisão integrativa. J. res.: fundam. care. Online, v. 8, n. 2, p. 4212-4222, abr/jun., 2016. Disponível em:<http://www.seer.unirio.br/index.php/cuidadofundamental/article/view/3983/pdf 185 9> Acesso em: 14. Out. 2018.

RODRIGUES, Diego Pereira et al. Estresse na unidade de Terapia Intensiva: Revisão Integrativa. Rev enferm UFPE Online, Recife, v. 7, n. (esp), p. 4217-26, maio., 2013. Disponível em:<http://www.revista.ufpe.br/revistaenfermagem/index.php/revista/article/download/4 651/6337.> Acesso em: 10.Out.2018. 
SILVA, Fabíola Soares da; SANTOS, Iraci dos. Expectativas de familiares de clientes em uti sobre o atendimento em saúde: estudo sociopoético. Esc Anna Nery Rev Enferm, v. 14, n. 2, p. 230-235, abr-jun., 2010. Disponível em: < http://www.scielo.br/pdf/ean/v14n2/03.pdf > Acesso em: 14. Out.2018.

SILVA, Fernanda Duarte dos et al. Discursos de enfermeiros sobre humanização na unidade de terapia intensiva. Esc Anna Nery (impr.), v. 16, n. 4, p. 719- 727, out-dez., 2012. Disponível em: < http://www.scielo.br/pdf/ean/v16n4/11.pdf> Acesso em: 14. Out. 2018.

SILVA, Adriane José de Souza et. al. Assistência de enfermagem na UTI: Uma Abordagem Holística. Revista Eletrônica de Enfermagem do Centro de Estudo de Enfermagem e Nutrição, v.1, n.1, p.1-16, jan-jun., 2010. Disponível em: < https://pt.scribd.com/document/88515380/Assistencia-de-Enfermagem-na-UTI> Acesso em: 15. Nov.2018.

SILVEIRA, Rodrigo Euripedes da; CONTIM, Divanice. Educação em saúde e prática humanizada da enfermagem em unidades de terapia intensiva: estudo bibliométrico. J. res: fundam. care. Online, v. 7, n. 1, p. 2113-2122, jan/mar., 2015. Disponível em: $<$ http://www.seer.unirio.br/index.php/cuidadofundamental/article/view/1589/pdf 1463> Acesso em: 14. Out. 2018. 